\title{
CONTRADIÇÕES ENTRE A GRANDE DEMANDA E A PEQUENA OFERTA DO CURSO TÉCNICO EM HEMOTERAPIA NO BRASIL
}

\author{
CONTRADICTIONS BETWEEN THE GREAT DEMAND AND THE SMALL \\ OFFER OF THE HEMOTHERAPY TECHNICIAN COURSE IN BRAZIL
}

CONTRADICIONES ENTRE LA GRAN DEMANDA Y LA PEQUEÑA

OFERTA DEL CURSO DE TÉCNICO DE HEMOTERAPIA EN BRASIL

\author{
Lucília Nunes de Assis ${ }^{1}$ \\ Marilene Barros de Melo $^{2}$ \\ Luiz Carlos Brant Carneiro ${ }^{3}$ \\ Luciana Souza d'Ávila ${ }^{4}$ \\ Priscila Lilibete Viana de Faria ${ }^{5}$
}

Resumo As regulamentações do setor sangue no Brasil passaram a exigir níveis de formação específicos voltados para os conhecimentos técnicos e práticos de hemoterapia e imunohematologia. O presente artigo objetivou identificar, compreender e analisar as imagens, ideias e percepções acerca do curso técnico em hemoterapia ministrado em uma escola de saúde pública da Região Sudeste do país. Metodologicamente, tratou-se de uma pesquisa-ação realizada entre março de 2012 e dezembro de 2013, com docentes, discentes e referências técnicas do curso. Constatamos que o curso foi considerado relevante, com bom conteúdo programático, apesar de sua centralização em uma capital. Concluímos que formação em hemoterapia se faz urgente, entretanto a inserção de técnicas no âmbito do processo e das relações do trabalho neste campo é marcada por fragilidades e ausência de diretrizes.

Palavras-chave hemoterapia; saúde pública; educação técnica de nível médio em saúde.
Abstract The blood sector regulations in Brazil started to require specific levels of schooling geared to technical and practical knowledge of hemotherapy and immunohematology. This article aimed to identify, understand and analyze the images, ideas and perceptions about hematology y technical course taught in a school of public health, in Brazil. Methodologically, this was action research carried out between March 2012 and December 2013, with teachers, students and technical references. We found that the course was considered relevant, with good content, despite its centralization in the city in the southeast of the country. We conclude that schooling in hematology is done urgently, however, inserting techniques and process of labor relations in the field of Hematology is marked by weakness and absence of the guidelines.

Keywords hemotherapy; public health; medium-level technical education in health.

(cc) BY Este é um artigo publicado em acesso aberto sob uma licença Creative Commons. 


\section{Introdução}

A habilitação de técnicos em hemoterapia é uma qualificação nova na área da saúde e a descrição de competências específicas se faz urgente e deve levar em consideração as diretrizes curriculares dispostas no Catálogo Nacional de Cursos Técnicos do Ministério da Educação e Cultura (MEC).

Até o ano de 2007, a formação de técnicos em hemoterapia, em sua totalidade, ocorria em instituições privadas de ensino. Desde 2009, áreas preferenciais para a formação técnica foram incluídas no Programa de Formação de Profissionais de Nível Médio para a Saúde (Profaps) com o objetivo de ampliar numérica e qualitativamente o contingente estratégico dos trabalhadores técnicos para a saúde, em prol da consolidação do SUS (Brasil, 2009b).

As diretrizes e orientações curriculares elaboradas para a Formação Técnica, por meio do Ministério da Saúde (MS), apontaram como áreas prioritárias a citotecnologia, a hemoterapia, a radiologia, e a vigilância em saúde. A responsabilidade pela organização desses cursos fica a cargo de Escolas Técnicas do SUS, Escolas de Saúde Pública (ESPs) e Centros Formadores vinculados, em sua maioria, aos gestores municipais e estaduais de saúde. Essas unidades de ensino conformam a Rede de Escolas Técnicas do Sistema Único de Saúde (RET-SUS), segundo legislação vigente, e se constituem como resposta às necessidades de formação do pessoal de nível médio atuante no setor, em coerência com a atribuição do SUS de ordenar a formação de Recursos Humanos em Saúde - RHS (Brasil, 2009a).

A RET-SUS é composta, no total, por quarenta unidades de ensino voltadas à formação e educação permanente na área da saúde. Dos 25 estados e mais o Distrito Federal com tais instituições presentes, apenas em 17 estados (Acre, Amazonas, Ceará, Maranhão, Mato Grosso do Sul, Pará, Paraíba, Pernambuco, Piauí, Rio de Janeiro, Rio Grande do Norte, Rondônia, Roraima, Santa Catarina, São Paulo, Sergipe e Tocantins) há oferta do Curso Técnico de Hemoterapia (CTH), o que evidencia a não consolidação da oferta deste curso em comparação com a demanda e respectiva regulamentação da profissão ou da ocupação (Brasil, 2016).

A oferta do $\mathrm{CTH}$, objeto deste estudo, veio responder a uma demanda do MS quanto às ações voltadas para a formação/qualificação do pessoal atuante no âmbito das unidades hemoterápicas (banco de sangue) do SUS. A construção do currículo desses cursos técnicos deu-se por meio de oficinas regionais realizadas pela Coordenação das Ações Técnicas da Secretaria de Gestão do Trabalho e da Educação na Saúde (SGETS/MS). As oficinas contaram com a parceria da Organização Pan-Americana de Saúde (Opas), a participação das ESPs e das universidades federais tecnológicas e tiveram por produtos a consolidação e a validação de mapas de competências profissionais e de orientações 
curriculares. No caso do CTH em questão, essa responsabilidade coube a uma ESP que contou com o apoio da SGETS/MS e de um Hemocentro.

Ao considerar a escassa produção acadêmica sobre a formação técnica em hemoterapia, segundo Evangelista (2015), relacionada ao recente surgimento da habilitação ou vinculada ao processo de consolidação do campo de formação no país, faz-se importante a produção deste trabalho. O presente artigo objetivou identificar, compreender e analisar as imagens, ideias e percepções de alunos, docentes, referências técnicas/administrativas e coordenadores do curso técnico em hemoterapia ministrado em uma ESP situada na Região Sudeste do país.

\section{Contextualização histórica}

O século XX celebrou novos parâmetros para a prática transfusional no Brasil. Com padrões científicos, buscou-se garantir a qualidade das transfusões, pautando-se na seleção dos doadores e na vinculação da assistência transfusional com centros de estudos e de pesquisa (Junqueira, Rosenblit, Hamerschlak, 2005). Entretanto, foi apenas na década de 1980, com o marco da criação da Fundação Pró-Sangue, vinculada ao MS e instituída pela portaria interministerial n. 7/1980 (Brasil, 2002), que se desenvolveu a implementação da política pública do sangue, condutora da criação de um modelo mais eficaz de boas práticas para hemoterapia, conforme investigação de Pimentel (2006). Entre as ações adotadas para concretizar essa garantia, algumas regulamentações se destacam: a lei n. 7.649, sancionada em 25 de janeiro de 1988 (Brasil, 1988a); a Constituição Federativa do Brasil (Brasil, 1988b), a lei n. 10.205/2001 (Brasil, 2001), a lei n. 10.972/2004 (Brasil, 2004) e a portaria GM/MS n. 1.353/2011 (Brasil, 2011).

A lei n. 7.649/1988 veio assegurar o cadastro obrigatório dos doadores de sangue e exames laboratoriais no sangue coletado, o que evita a transmissão de enfermidades presentes no sangue. A Constituição Federativa do Brasil (Brasil, 1988b), em seu artigo 199, $\S 4^{\circ}$, vetou qualquer tipo de comercialização do sangue e seus derivados e estabeleceu a necessidade de lei específica que contemple as condições e requisitos para a coleta, pesquisa, tratamento, processamento e transfusão. Acrescenta, em seu artigo 200, que cabe ao SUS o controle e a fiscalização dessas ações.

Em 1995, a portaria GM/MS n. 127, de 8 de dezembro de 1995, ao instituir o Programa Nacional de Inspeção em Unidades Hemoterápicas - PNIUH -, definiu os serviços que compõem a rede de sangue e hemoderivados no âmbito do SUS.

A lei n. 10.205/2001 (Brasil, 2001) veio regulamentar o $§ 4^{\circ}$ do artigo 199 da Constituição Federal, com vistas a ordenar as questões relativas à coleta, 
processamento, estocagem, distribuição e aplicação do sangue, seus componentes e derivados. Designa um Sistema Nacional de Sangue, Componentes e Derivados (Sinasan), responsável pela gestão da Política Nacional de Sangue, Componentes e Hemoderivados, de maneira a garantir e harmonizar a autossuficiência desse setor nas três esferas do SUS.

De acordo com Junqueira, Rosenblit e Hamerschla (2005), esta política veio ordenar o Sistema Hemoterápico no Brasil, com a criação de hemocentros nas principais cidades do país. O artigo $7^{\circ}$ da lei n. 10.205/2001 (Brasil, 2001) regulamenta o exercício de atividades hemoterápicas em instituições, e preconiza a necessidade de autorização anual pelo Órgão de Vigilância Sanitária. Nesta perspectiva, segundo Garcez (2008), a Agência Nacional de Vigilância Sanitária (Anvisa) torna-se responsável por formular políticas públicas, gerenciar, controlar e fiscalizar a hemoterapia brasileira e determina que a competência pela prestação de serviços hemoterápicos é da hemorrede pública estadual e municipal.

O decreto n. 3.990/2001 (Brasil, 2001) institucionalizou a organização e funcionamento do Sinasan. A lei n. 10.972, de 2 de dezembro de 2004 cria a Hemobrás - Empresa Brasileira de Hemoderivados e Biotecnologia -, responsável por garantir o fornecimento de medicamentos hemoderivados ou produzidos por biotecnologia aos pacientes do SUS.

O Regulamento Técnico de Procedimentos Hemoterápicos foi aprovado pela portaria GM/MS n. 1.353/2011 (Brasil, 2011). Esta portaria estabeleceu um protocolo completo sobre os procedimentos técnicos e a organização de serviços hemoterápicos. Determinou ainda que para a melhoria do processo de atenção e o acolhimento dos candidatos à doação, a qualificação dos técnicos da hemorrede e de suas unidades vinculadas de saúde seria de responsabilidade de seus respectivos serviços.

Estas regulamentações passaram a exigir níveis de formação específicos voltados para conhecimentos técnicos e práticos de hemoterapia e hematologia (Pronko et al., 2011).

A primeira exigência de formação para trabalhar com processos tecnológicos específicos na área de hemoterapia foi designada na resolução n. 2/72 do antigo Conselho Federal de Educação (CFE) que preconizava a necessidade da habilitação em auxiliar técnico de banco de sangue. Em 1990, o parecer n. 59 deste mesmo Conselho estabelece formações distintas em técnico em hemoterapia e técnico de hematologia. Descreve a ocupação do técnico em hemoterapia como um profissional de $2^{\circ}$ grau que possui entre as suas funções, a participação no recrutamento de candidatos a doadores de sangue, o processamento do sangue colhido, o armazenamento, a expedição do sangue, a aplicação transfusional e o controle de qualidade. Explicita que as atividades desse profissional devem ser realizadas sob a supervisão de um médico 
hemoterapeuta ou hematologista. Caso não existam estes especialistas, qualquer profissional graduado em medicina poderá assumir a responsabilidade pelos serviços médicos, técnicos e auxiliares.

A Classificação Brasileira de Ocupações (CBO), do Ministério do Trabalho e do Emprego, passou a reconhecer o técnico em hemoterapia como profissão desde março de 2014 e acompanha a ampliação da habilitação técnica pela RET-SUS iniciada em 2009 (Pronko et al., 2011). Assim, a consolidação de um currículo de competências específicas da área encontra-se em desenvolvimento, conforme diretrizes curriculares dispostas no Catálogo Nacional de Cursos Técnicos do MEC.

\section{Tipo de estudo e condução}

Trata-se de um estudo transversal, qualitativo, que tem como participantes discentes, docentes, gestores, referências técnicas e administrativas de um curso técnico em hemoterapia, ofertado por uma ESP. O aporte teórico fundamentou-se, assim, na pesquisa-ação, na educação permanente em saúde e na sociologia das profissões. Esta opção sustentou-se na sua possibilidade de suscitar a participação ativa e emancipatória dos sujeitos, para comtemplar suas experiências e favorecer a identificação de necessidades e interesses (Franco, 2005; 2008; Thiollent, 2011; Toledo, Giatti e Pelicioni, 2012; Ceccim e Feuerwerker, 2004; Ceccim, 2005)

$\mathrm{O}$ curso foi analisado em três etapas - inicial, intermediária e final. $\mathrm{Na}$ etapa inicial procedeu-se a pesquisa documental para contextualização do objeto de estudo. Realizaram-se entrevistas individuais com atores-chave da coordenação do curso e aplicação de questionários a discentes e docentes. $\mathrm{Na}$ etapa intermediária, houve grupos focais para docentes e discentes. Por último, realizaram-se oficinas segundo concepção de Afonso (2002), que aplica como ferramenta o Planejamento Estratégico Situacional (PES), conforme proposição de Matus (1993). Esta última etapa envolveu sujeitos das instituições responsáveis pelo desenvolvimento do curso, como o superintendente de educação, o coordenador do Núcleo do $\mathrm{CTH}$, as referências técnicas, o técnico administrativo, um pedagogo e o representante da Secretaria de Ensino.

Os questionários semiestruturados, as entrevistas e os grupos focais (estes dois últimos orientados por um roteiro de perguntas) abordaram a formação e a trajetória profissional dos envolvidos; aspectos do processo pedagógico, da infraestrutura (materiais, equipamentos, espaço físico, recursos humanos) e da gestão (implementação, monitoramento e avaliação) do curso; e informações relativas à evasão dos alunos.

As oficinas incluíram os momentos explicativo e estratégico com o objetivo de discutir os avanços e desafios ao longo do curso, os problemas, suas 
causas e consequências. Buscou-se também desenhar ações propositivas para transformar a realidade vigente e elaborar um plano de ação para os cursos a serem ofertados futuramente.

A análise descritiva de parte das informações obtidas com a aplicação dos questionários foi organizada segundo a distribuição de médias e frequências. A análise do conteúdo qualitativo dos documentos, questionários, entrevistas, grupos focais e oficinas iniciou-se fundamentada na leitura intensiva do material a fim de identificar unidades temáticas (Minayo, 2010).

A hermenêutica-dialética serviu como base para a análise das informações agrupadas, segundo unidades temáticas como: Institucionalização do curso; Infraestrutura para operacionalização do curso; Projeto pedagógico do curso; Desenvolvimento do conteúdo teórico e prático do urso; Monitoramento/ Avaliação do curso; Avaliação e adesão do aluno.

Essa técnica de análise conseguiu traduzir, por meio de complementaridades e oposições, a síntese dos processos comunicativos compreensivos e críticos, ao considerar múltiplas fontes de informação, contexto histórico, forma da linguagem (oral ou escrita), papel do autor ou ator na situação e o poder que sustenta e permeia os processos envolvidos (Habermas, 1987).

Buscou-se assim compreender as condições sob as quais surgem os discursos, com reconhecimento da polaridade existente entre a familiaridade e a estranheza, de quem fala e de quem escuta, além do entendimento de que não existe ponto de vista fora da história e de que nada é eterno, fixo ou absoluto. Essa análise pretendeu uma abordagem do recorte da realidade estudada pela sua compreensão e crítica.

Este estudo foi aprovado pelo Comitê de Ética em Pesquisa do Centro de Estudos Odontológicos do Instituto de Previdência Social do Estado de Minas Gerais, por meio do parecer n. 58.

\section{Desvelamento do campo da hemoterapia e estruturação do curso}

Para a formulação e implementação do curso, fez-se necessário desvelar o campo da hemoterapia. Procurou-se contextualizá-lo historicamente por meio das políticas públicas formalizadas, identificar a estruturação teórica e prática, bem como registrar as funções relacionadas à sua rede de serviços. A instituição gestora da rede é o Hemocentro que tem como responsabilidade a coordenação das ações e serviços prestados por hemocentros regionais, hemonúcleos, unidades sorológicas, serviços de hemoterapia, unidade de coleta e transfusão, agência transfusional, posto de coleta e serviços de hemoterapia distribuidor. Tem ainda como função: prestar assistência e apoio hemoterápico à rede de serviços; prestar serviços de ensino e pesquisa; desenvolver as ações de coleta de sangue, respectivo uso e distribuição de componentes sanguíneos, com a publicização de normas técnicas adequadas 
e seguras. Sua localização é preferencialmente na capital do estado e representa o serviço de maior incorporação tecnológica.

O pouco conhecimento sobre o campo hemoterápico constituiu um desafio no âmbito da formação/qualificação não somente para a instituição de ensino responsável pela condução do curso, mas também para o MS (Minas Gerais, 2010a; 2010b). Segundo um dos docentes que participou do grupo focal, o MS, em busca de minimizar esta situação, a partir de 2010, organizou uma comissão para discutir as diretrizes do curso técnico em hemoterapia. A comissão promoveu uma ampla discussão com várias instituições da RET-SUS, que envolveu outros cursos técnicos da área da saúde, hemocentros, secretarias de saúde, universidades e representantes do MS para definir os parâmetros orientadores do plano e o currículo do novo curso técnico em questão.

A proposta do curso foi aprovada na Comissão Estadual Permanente de Integração Ensino-Serviço (CIES) e formalizada por deliberação estadual da Comissão Intergestores Bipartite (CIB-SUS) que estabeleceu a programação de uma turma piloto em modalidade presencial, que atenderia 20 alunos de um Hemocentro. Esse público específico não completou o número preconizado pela deliberação, conforme informações do grupo focal dos discentes. Fato que induziu a abertura de vagas para servidores de outras instituições de saúde. Entretanto, a divulgação do curso foi pouco eficaz, de acordo com alguns depoimentos.

O CTH, conforme percepção da servidora FC da Secretaria de Ensino da ESP, apresentou dificuldades quanto aos trâmites para a institucionalização na Secretaria Estadual de Educação (SEE). A sua formação multidisciplinar exigiu maiores cuidados na elaboração da ementa das disciplinas.

Segundo a participante SC, coordenadora da ação educativa da Escola, a oferta de formação e qualificação do técnico em hemoterapia descentralizada territorialmente pelo MS poderá constituir-se uma limitação para o desenvolvimento do curso. A peculiaridade de sua habilitação torna sua descentralização mais complexa em relação aos demais cursos técnicos em saúde, visto que há determinados conteúdos práticos passíveis de serem desenvolvidos apenas no hemocentro da capital, o que requeria planejamento e programação elaborados.

Para outro participante, referência técnica do $\mathrm{CTH}$, a especificidade do conteúdo prático a ser desenvolvido pressupõe a disponibilidade de ambientes laboratoriais estruturados para a realização de atividades pertinentes à sorologia e ao fracionamento, por exemplo, e carece de recursos nem sempre disponíveis no âmbito dos hemocentros regionais. Tal fato poderá comprometer a viabilidade da descentralização das turmas, pois o aluno em algum momento teria que realizar uma parte do curso na capital e outra na sede do hemocentro estadual.

As oficinas de elaboração do CTH possibilitaram constatar a existência do poder que perpassa o domínio da técnica em uma instituição de serviço hemo- 
terápico, e as resistências para a sua socialização sob a forma de capacitação para uma 'demanda reprimida'. Estrategicamente, conduziram-se discussões amplas sobre o caráter político das dificuldades para a regulamentação da profissão; os bloqueios para a inserção dos alunos no mercado; os objetivos instituintes do curso e os desafios teóricos e metodológicos de uma primeira oferta de curso técnico em hemoterapia. Faz-se constar que tais questões também foram tema de discussão em outros estudos relacionados à formação técnica para o SUS (Morosini et al., 2013).

A elaboração do Plano de Curso foi considerada um momento-chave, pois alterações posteriores, durante o desenvolver do curso, seriam difíceis, segundo depoimentos de alguns docentes. Na visão de alguns participantes da pesquisa, a relação entre MS, ESP e Hemocentro carecia de maior articulação, uma vez que os objetivos de cada uma destas instituições não eram claros. Esta situação complicou-se com a publicação das diretrizes curriculares do CTH sem a presença de um referencial capaz de fundamentar o plano da ação educativa. Tal material de apoio só veio a ser disponibilizado pelo MS na forma de um livro texto específico à formação do técnico em hemoterapia, um ano após a operacionalização do curso (Brasil, 2013). Foram considerados critérios para a participação como discente do curso: ter ensino médio concluído ou estar cursando o $3^{\circ}$ ano do ensino médio; ter idade mínima de 18 anos; ser profissional de nível médio no SUS, preferencialmente com vínculo efetivo e trabalhador em serviços de hemoterapia.

\section{Gráfico 1}

Tempo de experiência profissional dos discentes do Curso Técnico em Hemoterapia em assistência no setor público e gestão e assistência no setor privado.

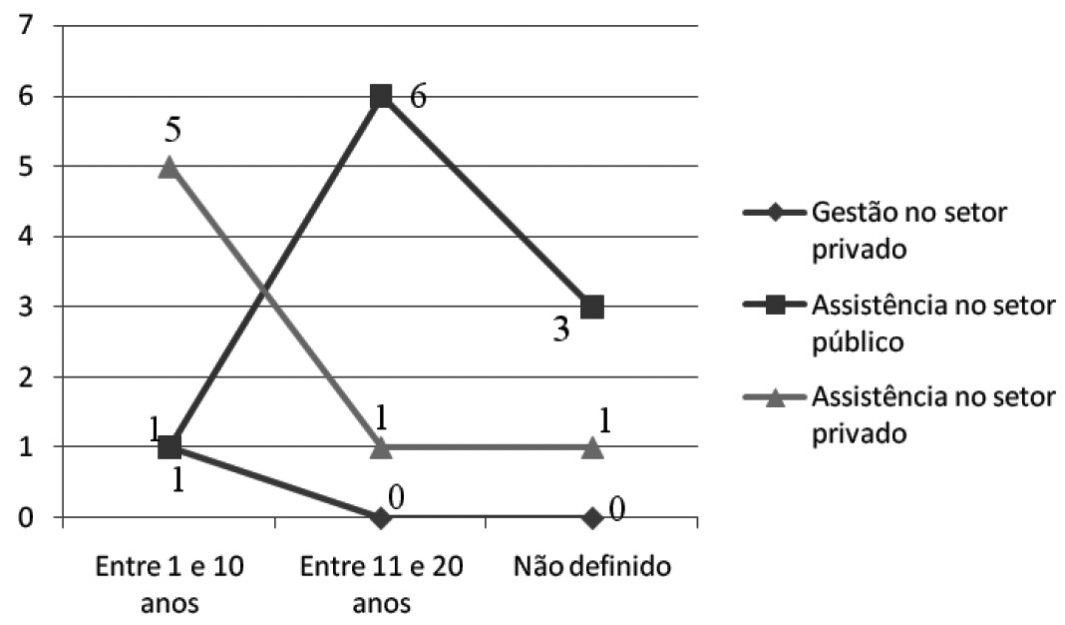

Fonte: Entrevistas com discentes do Curso Técnico de Hemoterapia, ESP-MG/2012. 
O CTH iniciou com uma turma noturna de 20 alunos, oriundos do $\mathrm{He}$ mocentro. Os questionários para elaboração do perfil dos alunos - taxa de resposta de $70 \%(n=14)$ - indicaram que a maioria era do sexo feminino $(12 ; 86 \%)$ e se encontrava na faixa etária acima de 41 anos $(9 ; 64 \%)$. Quanto à formação, nove discentes já possuíam outro curso técnico; o mais citado foi o curso em patologia clínica. Apenas cinco relataram possuir curso superior completo. Quanto ao tempo de experiência, a maioria trabalha no setor público e tem entre 11 e 20 anos de experiência, como pode ser visto no Gráfico 1.

Quanto às expectativas, as mais citadas foram: aprimoramento da prática profissional; enriquecimento curricular; aquisição de conhecimentos teóricos; melhoria acerca do entendimento da realidade em que atua; incremento do plano de carreira, cargos e salários. Os participantes do grupo focal discente afirmaram interesse pessoal, cientes que o curso não representaria garantia de melhoria salarial ou benefícios em curto prazo. Fato que reforçou a percepção da coordenação de que o curso oferece um produto, a formação técnica em hemoterapia, mas que não implicaria em resultados imediatos, ou seja, no reconhecimento dessa formação no Plano de Carreira Cargos e Salários do estado.

Questionados sobre a origem da demanda para participação no curso, nove alunos afirmaram que a motivação foi pessoal; sete afirmaram ter sido por demanda estadual e nenhum citou o nível municipal. Para 12 discentes, o ingresso foi voluntário. Apenas um afirmou que a participação foi obrigatória, mas que havia um desejo anterior.

O discurso do grupo focal dos discentes evidenciou que alguns obtiveram informações sobre o curso no próprio serviço, por meio de notícia no mural ou por divulgação da chefia. Houve relato de chefias que estimularam a participação do servidor, porém, no caso do pessoal administrativo, a realização do curso teve o significado de maior fixação no setor. Constatou-se que a maioria dos discentes era do Hemocentro. Cinco discentes relataram já ter realizado cursos com conteúdo e temas afins ao do CTH; o mais citado foi o curso técnico em patologia clínica.

Para os docentes e referências técnicas do serviço, o curso poderia ser simplificado no que tange ao conteúdo teórico-prático. Seria mais efetivo e favoreceria a participação de um público alvo demandante de qualificação. Como técnicos em hemoterapia, devidamente certificados por uma instituição de ensino reconhecida socialmente, estes trabalhadores teriam maior força política na luta pela progressiva instituição do cargo público, além de aumentar as chances de serem absorvidos pelo mercado de trabalho em geral.

\section{Desenvolvimento e percepções acerca do curso: conquistas e fragilidades}

A análise da composição do quadro docente do CTH apontou que o Hemocentro estimulou seus servidores e colaboradores - funcionários do quadro 
próprio, cedidos e terceirizados - para atuarem nas atividades de qualificação e capacitação. Desta forma, acreditava-se que poderiam atuar juntamente com a ESP no levantamento inicial da demanda para habilitação técnica de trabalhadores de nível médio.

No que se refere ao desenvolvimento do curso, segundo alguns depoimentos, a Escola poderia ter assumido um papel mais propositivo e discutido a importância da regulamentação da profissão. Desta forma, cumpriria sua dimensão política no âmbito dos serviços de saúde e fortaleceria seu reconhecimento social.

A seleção de docentes foi um momento crítico. A especificidade de conhecimentos aliada à necessidade de conciliar carga horária do curso com o horário de serviço constituiu grandes desafios. Entretanto, a dificuldade maior, principalmente do docente local, foi a baixa remuneração.

\section{Infraestrutura}

O não funcionamento de vários setores da ESP no período noturno do curso dificultou a realização de atividades básicas e requereram o deslocamento do docente no horário do serviço para resolver questões com a coordenação. $\mathrm{O}$ espaço físico das salas foi apontado como adequado ao desenvolvimento das atividades. Entre os discentes, a ausência de um crachá ou carteira de identificação para facilitar o acesso a serviços e dependências do curso, a falta de segurança na região, a evidente ausência de um vigilante ou guarda municipal, a cantina sem atendimento noturno e o fato de o laboratório de dispersão servir de depósito de material foram os principais pontos negativos da infraestrutura.

A falta de experiência da ESP na compra de materiais específicos à hemoterapia foi a principal dificuldade relatada pela coordenação do CTH, apesar da disponibilização de recursos para a aquisição de materiais e apoio técnico do Hemocentro. Havia também determinantes estruturais relacionados ao problema da compra e distribuição dos equipamentos do Curso Técnico de Hemoterapia.

É necessário ressaltar que a ESP foi a única instituição executora desse curso no país que se dispôs a fazer aquisição de equipamentos/materiais, inclusive como forma de tornar a proposta do curso mais atrativa para a rede de serviços, considerando que a origem dos respectivos docentes e discentes foi quase que exclusivamente do hemocentro estadual. A equipe técnica responsável pelo desenvolvimento do curso contou com um especialista para prestar assessoria no que tange ao conteúdo programático, ao corpo docente e à coordenação. O corpo técnico contou ainda com um coordenador pedagógico, uma secretária escolar e uma equipe técnico-administrativa. 


\section{Plano de curso e projeto pedagógico}

Atos específicos do campo hemoterápico, como coleta de sangue e procedimentos relacionados à transfusão, são inerentes à prática do técnico em hemoterapia. Práticas estas que implicam em embates com a regulamentação profissional do campo da enfermagem. Essa situação foi exposta na oficina em que estavam presentes diversos representantes de setores da ESP e na qual se questionou que órgão regulamentará a profissão de técnico em hemoterapia.

Para alguns profissionais, o curso técnico em hemoterapia deveria ter por precedente outra formação técnica em saúde, fato que não corresponde à regulamentação dos cursos técnicos na área. Houve controvérsia no grupo focal de docentes quanto à capacidade do curso em desenvolver a competência técnica específica para o exercício da nova profissão, ao se considerar a amplitude da sua atuação. A ausência da elaboração conjunta de um plano de curso comprometeu o processo ensino-aprendizagem, pela fragmentação dos temas nas unidades. Por sua vez, a causa desse problema foi associada ao fato do MS não ter repassado o guia curricular elaborado durante as discussões técnicas das diretrizes curriculares.

Os depoimentos de alguns docentes apontaram que a ESP deveria ter assumido um papel mais propositivo e não apenas esperar que os professores definissem todo o conteúdo programático e sua operacionalização. Esta situação foi relativizada por alguns participantes ao considerarem o fato do curso ser uma oferta ainda recente no âmbito da RET-SUS, desenvolvido apenas em outros três estados brasileiros na ocasião em que foi ministrado pela primeira vez.

\section{Conteúdo programático}

Discussões prévias entre técnicos da área em âmbito nacional embasaram o conteúdo programático do plano do curso técnico da hemoterapia. A ESP contratou uma referência técnica apenas para assessorar na conformação dos conhecimentos teórico-práticos. Na opinião de uma entrevistada, esse papel foi exercido por um ator estratégico, tanto pela sua atuação no Hemocentro estadual central, como também por ter participado na elaboração das diretrizes curriculares do curso em âmbito federal.

A carga horária mínima definida foi de 1.200 horas, excluindo-se o estágio supervisionado. O conteúdo programático do CTH foi organizado segundo três módulos, em um total de 1.320 horas, com momentos de concentração (800 horas) e dispersão (520 horas). Conforme consta no Plano de Curso, "devido às peculiaridades para a formação do Técnico em Hemoterapia”, a ESP 
ofertou o curso sem saídas intermediárias, ou seja, opção única de conclusão ao final dos três módulos. Estes módulos e suas respectivas unidades são sintetizadas no Quadro 1.

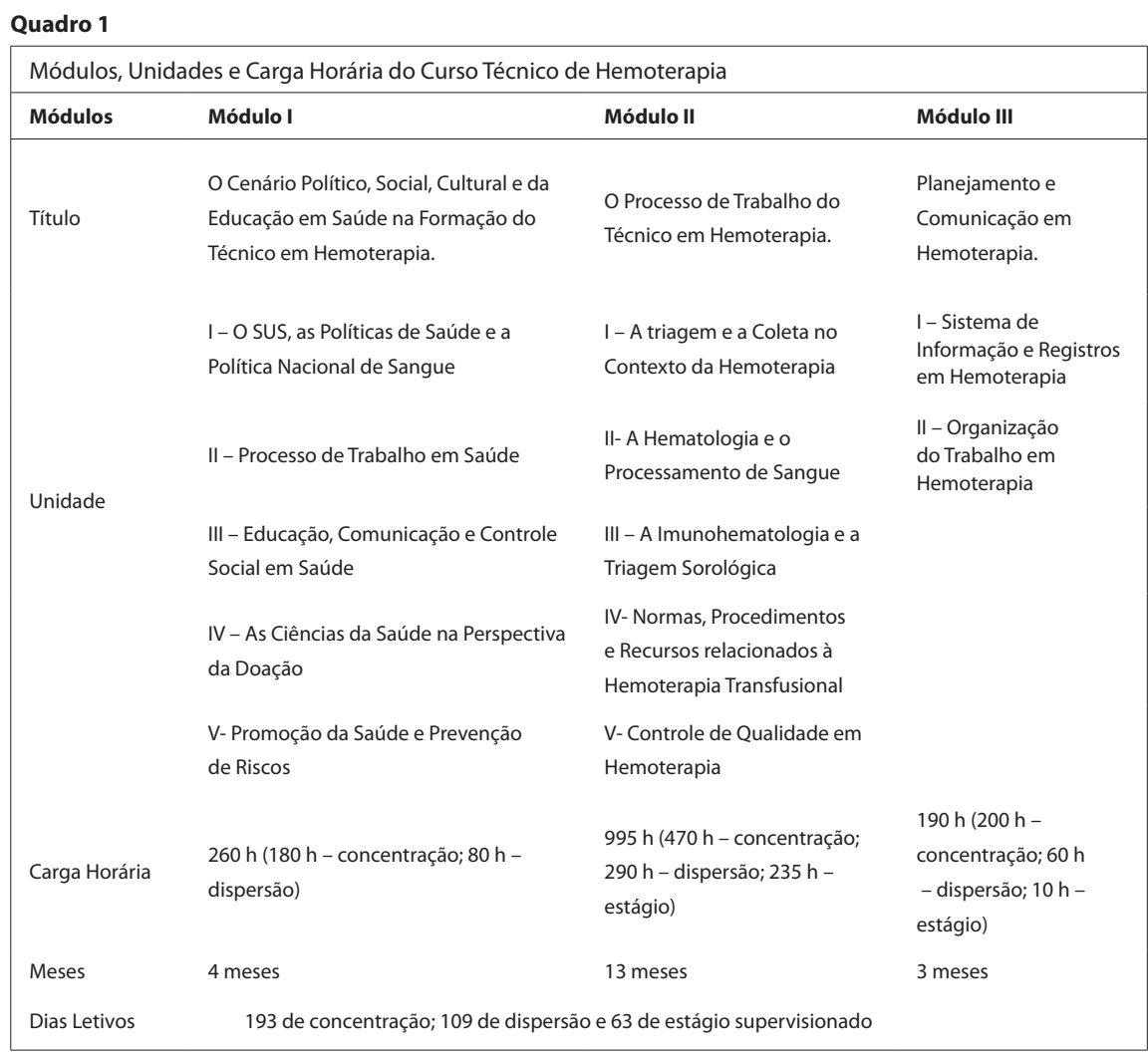

Fonte: Plano do Curso Técnico de Hemoterapia da ESP-MG/2012.

\section{Material didático}

A coordenadora do CTH apontou que não houve elaboração prévia do material didático, e que esta responsabilidade ficou a cargo do docente de cada unidade didática. Esse fato gerou ansiedade para os docentes. Para lidar com esta situação, realizaram-se reuniões com os docentes antes de cada unidade de ensino. Ainda que as pedagogas estivessem articuladas com os docentes, no processo ensino-aprendizagem, não havia avaliação sistematizada do material didático empregado.

A ausência de um material didático com a estrutura do conteúdo teóricoprático do $\mathrm{CTH}$ comprometeu o projeto pedagógico, pois limitou a colaboração das pedagogas da ESP no aprimoramento didático do material. 


\section{Abordagem pedagógica}

A articulação da teoria e da prática em serviço proporcionada pelo curso foi percebida como meio de qualificar, aprimorar e transformar o processo de trabalho dos discentes e trabalhadores do Hemocentro, segundo a perspectiva da educação permanente em saúde, conforme proposição de Ceccim e Feuerwerker (2004) e Ceccim (2005). A articulação foi associada à adoção do currículo integrado pela ESP como "uma imersão do discente no seu ambiente de trabalho", bem como das situações específicas que envolveram o curso, como a educação de adultos e o longo tempo de afastamento dos estudos pelos discentes participantes.

A formação do profissional técnico em hemoterapia, como estratégia de qualificação da prática, requer um criterioso desenvolvimento das habilidades teórico-práticas, como forma de evidenciar o diferencial que este profissional tem em relação aos práticos, de acordo com Garcez (2008). Foi considerado eficiente o momento de concentração seguido da dispersão/estágio, o que possibilitou a vivência teórico-prática, o esclarecimento de dúvidas e o aprendizado do conteúdo tratado.

O domínio de certos conteúdos foi uma das estratégias de consolidação desse campo de conhecimento no âmbito técnico e, consequentemente, no âmbito da profissionalização. A importância da regulamentação da área contribuiu para que esses trabalhadores, segundo suas falas, entendessem a postura da chefia quanto à rigorosidade do cuidado no processo de trabalho.

Foi abordada a importância do docente de dispersão ser o mesmo da concentração, devido à lacuna (de tempo) entre esses dois momentos. Esse problema teve como uma das causas o fato de o docente servidor ter que repor em serviço a carga horária dispensada para o acompanhamento dos discentes na parte prática do curso, o que inviabilizava que o mesmo assumisse as atividades da concentração, dispersão e estágio. Outro fator complicador foi a situação de alguns docentes assumirem mais de uma disciplina.

A estratégia que se buscou foi o envio aos docentes de um modelo de plano de aula, de modo que a equipe pedagógica pudesse contribuir com o aperfeiçoamento da prática pedagógica e auxiliar na disponibilização de referencial bibliográfico como suporte técnico.

A participação e o envolvimento dos discentes foram facilitados pela turma reduzida e pela prática pedagógica fundamentada no currículo integrado (ensino-serviço). Acrescentaram que as recomendações recebidas favoreceram o maior dinamismo durante o desenvolvimento dos conteúdos programáticos com os alunos, com equilíbrio entre aulas expositivas e discussões dialogadas. Constatou-se também que tal apoio pedagógico não foi suficiente para aqueles que não tinham nenhuma experiência didática. 
A coordenação pedagógica do curso apontou a necessidade de um momento conjunto para trabalhar com os docentes e discentes do curso. Os docentes que não participaram do momento anterior da qualificação pedagógica não apresentaram disponibilidade para um novo encontro. Isto dificultou a construção de uma abordagem pedagógica adequada.

Foi levantada a hipótese de o curso convidar profissionais qualificados, não pertencentes ao quadro de servidores estaduais ou municipais, pois acreditava-se que estes teriam maior disponibilidade para a dedicação docente. Entretanto, essa proposta foi recusada, uma vez que a rede de serviços, especialmente para a parte prática do curso, atrela o mesmo aos servidores da rede de hemoterapia estadual.

\section{Campo de dispersão e estágio}

De acordo com os depoimentos de alguns docentes, houve um diálogo inicial com o responsável de campo de estágio para acordar o número de alunos. Definiu-se que o máximo seria de cinco alunos por momento de prática.

O Hemocentro garantiu horário protegido, ou seja, a liberação da carga horária de trabalho para os discentes realizarem o estágio, mas este acordo não foi considerado por todas as chefias imediatas, visto que em alguns casos houve dificuldade de participação do discente na atividade prática do curso por estar de plantão. Por sua vez, estes docentes constataram que o envolvimento da equipe de profissionais do Hemocentro na habilitação dos novos técnicos deixou a desejar.

Em que pesem as dificuldades, o momento prático do curso foi apontado pelos docentes como uma importante contribuição para a construção de vínculos entre os trabalhadores originários de diferentes setores do Hemocentro.

\section{Participação do discente no curso}

Alguns alunos desistiram logo no início do curso. O motivo foi a dificuldade de negociar com as respectivas chefias imediatas a liberação durante a jornada de trabalho para a realização das atividades práticas. Esses desistentes não eram trabalhadores do Hemocentro da Capital, mas da rede de serviço ou de outros hemocentros e agências transfusionais.

A ocupação das vagas, que se tornaram inativas em virtude da desistência de discentes, foram preenchidas de forma imediata por novos discentes dos serviços do Hemocentro ou da rede municipal, localizados na capital do estado, ao tomarem conhecimento da oferta do curso. Para tanto, realizaram nivelamento quanto ao conteúdo e inseriram-se nas atividades. Alguns servidores do Hemocentro, que não apresentaram interesse em participar, apresentaram como uma das justificativas o fato de o curso ser muito extenso. 
A realização noturna do curso foi um fator favorável à participação dos servidores do Hemocentro. Essa fundação estadual tem jornada de trabalho de 30 horas, muitos trabalhadores têm outros vínculos empregatícios, o que pode ter dificultado a sua participação no curso.

Alguns discentes questionaram o porquê de os momentos de concentração do curso também não ocorrerem no âmbito dos serviços, fato que evitaria deslocamentos. Os mesmos foram informados de que o Hemocentro, apesar de ofertar ações de ensino-pesquisa, não possuía habilitação para ofertar o curso técnico em questão, visto que a acreditação para a oferta de tal formação profissional estava atrelada a uma série de prerrogativas a serem cumpridas e avaliadas pela Secretaria e Conselho Estadual de Educação. A liberação para a participação no curso, seja dos discentes seja dos docentes, foi considerada inconveniente pelos gestores, principalmente no que tange à carga horária da concentração, daí a opção pela realização desse momento em período noturno.

O calendário das aulas de dispersão/estágio foi construído pelos próprios participantes para atender às especificidades do serviço. O curto período diário de estágio, no máximo duas horas, favoreceu a sua operacionalização em horário de trabalho.

Houve algumas dificuldades de participação daqueles que dependiam da liberação da chefia imediata. Esse desafio foi relacionado à situação de aumento da demanda dos doadores ou necessidade de corrigir determinado procedimento realizado (retrabalho), o que retinha participantes no serviço.

A desistência de alguns discentes se deu também por motivos pessoais. Poucos alegaram que o curso era difícil, ainda que o conteúdo fosse complexo para aqueles que não estavam inseridos na prática hemoterápica. Faz-se destacar que houve relato da não participação de servidores de um grande hospital público da capital por desconhecimento, decorrente da insuficiente divulgação do curso no serviço, ou por não conseguirem a liberação da chefia.

Os participantes da oficina esclareceram que, na metade do período, o curso já contabilizava cerca de $40 \%$ de desistência e era constante a busca ativa do aluno faltoso por parte da coordenação. Esses entrevistados chegaram a questionar a real demanda pelo curso frente à esta situação, o que apontou a necessária discussão entre gestão, instituição de ensino e trabalhadores da saúde sobre a coerência entre a formação do RHS e a empregabilidade (Chinelli, Vieira e Deluiz, 2013).

\section{Monitoramento e avaliação do processo ensino e aprendizagem}

A coordenação do curso não identificou problemas quanto à dificuldade de acompanhamento do curso pelos discentes. Os alunos foram avaliados ao final de cada unidade por competência, como apto ou não apto. Essa avaliação incluiu em conjunto o aprendizado teórico-prático. Os métodos de avaliação 
do discente incluíam a produção de relatórios e provas que variavam de acordo com o docente. Os alunos relataram que o curso possibilitou uma visão geral do processo de trabalho, e permitiu identificar o impacto de determinada atividade no conjunto das ações, o que favoreceu o aprimoramento do trabalho em equipe. Os métodos de avaliação, em geral, tanto do discente como do docente, foram considerados efetivos. Alguns docentes alegaram que poderia ter ocorrido maior incremento nesse processo, principalmente com uma participação mais efetiva do coordenador local do curso, no âmbito do serviço. O desenvolvimento do processo ensino-aprendizagem por meio de uma discussão problematizadora e dialogada favoreceu a avaliação periódica do discente. O dinamismo das aulas práticas também facilitou a percepção do docente sobre a evolução dos alunos.

Os docentes reclamaram do elevado número de relatórios a serem preenchidos para o registro do desenvolvimento do curso e acompanhamento dos alunos. Relataram ainda que em outras experiências de docência havia pessoal somente para ocupar-se dessa parte, compreendida como burocrática. De acordo com alguns, isto comprometeu o interesse do docente em alguns módulos.

Em resposta, os participantes da oficina esclareceram que os relatórios para o acompanhamento do processo ensino-aprendizagem já haviam sido suficientemente sintetizados. Para os representantes da secretaria de ensino da ESP presentes na oficina, os docentes e discentes do curso estão cientes da importância dos relatórios, pois eles são imprescindíveis para o registro do desenvolvimento do curso e emissão do certificado, de acordo com aspectos regulamentares do curso.

\section{Monitoramento e avaliação do curso}

A avaliação dos alunos ocorreu no fim de cada unidade e obtiveram-se suas impressões sobre a didática do docente e dos métodos da abordagem pedagógica. O processo de monitoramento e avaliação do curso foi prejudicado pela especificidade do conteúdo programático. O monitoramento do curso foi realizado unidade por unidade com deslocamentos periódicos ao Hemocentro para acompanhar o momento prático.

Constatou-se que não houve nenhum indicador de resultado pactuado em relação ao curso técnico em hemoterapia. Os indicadores, quanto às ações educativas desenvolvidas, são mais gerais e têm por foco a qualidade do processo. A sugestão foi que houvesse uma discussão mais ampla sobre os resultados, na tentativa de aproximá-lo do cotidiano laboral. 


\section{Considerações finais}

Os principais obstáculos do curso estiveram relacionados à baixa valoração da ação educativa pelos gestores dos serviços aos quais se vinculavam os discentes e docentes, trabalhadores da saúde. Esse fato pôde ser relacionado à baixa adesão e à evasão dos alunos, bem como às dificuldades dos docentes, qualificados pela formação e experiência profissional, em assumir a condução do conteúdo teórico-prático do curso.

Trata-se de um nó crítico sobre o qual a instituição de ensino possui pouca governabilidade, visto que mesmo a assinatura de um termo de compromisso entre gestores do ensino-serviço não garantiria a concessão de dispensa de parte da carga horária de trabalho para atividades da EPS. Um recurso estratégico seria a publicização dos resultados do próprio estudo, antes do início de novas turmas do curso, como maneira de informar e responsabilizar os gestores dos serviços de saúde quanto à necessária parceria com a instituição de ensino. Maior proatividade da CIES seria também essencial para o reforço do compromisso entre serviço, ensino e controle social (usuários, trabalhadores), para viabilidade da oferta de ações como o CTH.

As oficinas representaram o cerne do estudo e estão de acordo com a metodologia proposta, a pesquisa-ação. As informações obtidas pelos outros métodos permitiram também aos participantes repensarem as ações educacionais em questão ao operarem mudanças no sentido de redirecionar o curso de acordo com a demanda dos atores envolvidos.

A interação dos participantes da pesquisa promoveu uma relação de interdependência, conforme preconiza o princípio da alteridade. Esta concepção deu suporte à construção do objeto de estudo e ao desejo que a investigação transformasse a realidade instituída. Nesta perspectiva, o estudo constituiuse em ação coletiva e não se sustentou em modelos rígidos previamente determinados, pois exigiu, em seu percurso, a adoção de estratégias que se adequassem à realidade vigente e que privilegiassem a 'partilha do saber'; o que fez com que deixasse de ser um processo para ser o produto da mudança.

Concluímos que o curso representou um marco importante no exercício profissional do técnico em hemoterapia, o que contribuiu também para a sua formação global, visto que antes vários profissionais executavam funções técnicas, mas de forma fracionada e sem diretrizes teóricas e metodológicas. A qualidade do processo ensino-aprendizagem, a otimização do tempo do discente, a articulação dos temas do conteúdo programático e melhores condições para o servidor-docente desenvolver atividades teóricas e práticas constituem dimensões ainda a serem desenvolvidas. 
O curso, de modo geral, contribuiu para o crescimento profissional daqueles que trabalham no âmbito dos serviços de hemoterapia. Desta forma, visualizamos um amplo potencial para sua continuidade em outras instituições públicas de ensino. Acreditamos que o desenvolvimento e o aperfeiçoamento dos aspectos citados neste estudo contribuirão para a institucionalização do curso e o reconhecimento da profissão de técnico em hemoterapia.

\section{Colaboradores}

Lucília Nunes de Assis, Marilene Barros de Melo e Luciana Souza d'Ávila orientaram a pesquisa e trabalharam na análise dos dados e redação. Luiz Carlos Brant e Priscila Lilibete trabalharam na estruturação textual, redação e leitura crítica do artigo.

Resumen Las regulaciones del sector sangre en Brasil pasaron a exigir niveles de formación específicos dirigidos a los conocimientos técnicos y prácticos de hemoterapia e inmunohematología. El presente artículo objetivó identificar, comprender y analizar las imágenes, ideas y percepciones acerca del curso técnico de hemoterapia impartido en una escuela de salud pública de la Región Sudeste del País. Metodológicamente, se trató de una investigación-acción realizada entre marzo de 2012 y diciembre de 2013, con docentes, discentes y referencias técnicas del curso. Constatamos que el curso fue considerado relevante, con buen contenido programático, a pesar de su centralización en una capital. Concluimos que el entrenamiento en hemoterapia es urgente, al mismo tiempo que inserta técnicas no relacionadas al proceso ya las relaciones de trabajo en ese campo y marcadas por debilidades y ausencia de directrices.

Palabras clave hemoterapia; salud pública; educación técnica de nivel medio en salud. 


\section{Notas}

${ }^{1}$ Escola de Saúde Pública de Minas Gerais, Belo Horizonte, Minas Gerais, Brasil.

$<$ wcon.lucilia@terra.com.br>

Correspondência: Rua Uberaba, 12, CEP 30180-080, Barro Preto, Belo Horizonte, Minas Gerais, Brasil.

${ }^{2}$ Escola de Saúde Pública de Minas Gerais, Belo Horizonte, Minas Gerais, Brasil.

$<$ marilene.melo@esp.mg.gov.br>

${ }^{3}$ Universidade Federal de Minas Gerais, Escola de Enfermagem, Belo Horizonte, Minas Gerais, Brasil.

<brantluiz@ufmg.br>

${ }^{4}$ Escola de Saúde Pública de Minas Gerais, Belo Horizonte, Minas Gerais, Brasil. $<$ lucianasd14m@yahoo.com.br>

${ }^{5}$ Universidade Federal de Minas Gerais, Escola de Enfermagem, Belo Horizonte, Minas Gerais, Brasil.

<priscilalilibete@gmail.com>

\section{Referências}

AFONSO, Maria M. (org). Oficinas em dinâmica de grupo: um método de intervenção psicossocial. 1. ed. Belo Horizonte: Editora Casa do Psicólogo, 2002.

BRASIL. Constituição da República Federativa do Brasil de 5 de outubro de 1988. Diário Oficial da República Federativa do Brasil, Poder Executivo, Brasília, DF, 5 out.1988b. Seção I, p. 1 .

BRASIL. Decreto n. 3.990, de 30 de outubro de 2001. Regulamenta o artigo 26 da lei n. 10.205, de 21 de março de 2001, que dispõe sobre a coleta, processamento, estocagem, distribuição e aplicação do sangue, seus componentes e derivados, estabelece o ordenamento institucional indispensável à execução adequada dessas atividades. Diário Oficial da República Federativa do Brasil, Poder Executivo, Brasília, DF, 31 out. 2001. Seção I, p. 1.
BRASIL. Lei n. 7.649, de 25 de janeiro de 1988. Estabelece a obrigatoriedade do cadastramento dos doadores de sangue, bem como a realização de exames laboratoriais no sangue coletado, visando a prevenir a propagação de doenças e dá outras providências. Diário Oficial da República Federativa do Brasil, Poder Executivo, Brasília, DF, 27 jan. 1988a. Seção I, p. 1609.

BRASIL. Lei n. 10.205, de 21 de março de 2001. Regulamenta o $\S 4^{\circ}$ do artigo 199 da Constituição Federal. Diário Oficial da República Federativa do Brasil, Poder Executivo, Brasília, DF, 22 mar. 2001. Seção I, p. 1.

BRASIL. Lei n. 10.972, de 2 de dezembro de 2004. Autoriza o Poder Executivo a criar a empresa pública denominada Empresa Brasileira de Hemoderivados e Biotecnologia Hemobras e dá outras providências. Diário 
Oficial da República Federativa do Brasil, Poder Executivo, Brasília, DF, 03 dez. 2004. Seção I, p. 1 .

BRASIL. Portaria n. 1.353, de 13 de junho de 2011. Aprova o regulamento técnico de procedimentos hemoterápicos. Diário Oficial da República Federativa do Brasil, Ministério da Saúde, Brasília, DF, 14 jun. 2011. Seção I, p. 27.

BRASIL. Portaria n. 2.970, de 25 de novembro de 2009. Institui a Rede de Escolas Técnicas do SUS (RET-SUS) e dispõe sobre as diretrizes para a sua organização. Diário Oficial da República Federativa do Brasil, Ministério da Saúde, Brasília, DF, 26 nov. 2009a. Seção I, p. 48.

BRASIL. Portaria n. 3.189, de 18 de dezembro de 2009. Dispõe sobre as diretrizes para a implementação do Programa de Formação de Profissionais de Nível Médio para a Saúde (Profaps). Diário Oficial da República Federativa do Brasil, Ministério da Saúde, Brasília, DF, 22 dez. 2009b. Seção I, p. 97.

BRASIL, Ministério da Saúde. Portaria interministerial Bsb n. 7, de 30 de abril de 1980. In: CARNEIRO, Anna R.; LOPES, Maria E. D. (orgs.). Coletânea de legislação em hemoterapia e hematologia. Rio de Janeiro: Sociedade Brasileira de Hematologia e Hemoterapia (SBHH), 2002

BRASIL. Rede de Escolas Técnicas do SUS (RET-SUS). Técnico em Hemoterapia. Rio de Janeiro: RET-SUS, 2016. Disponível em: <http:// www.retsus.fiocruz.br/cursos/tecnico/tecnicoem-hemoterapia>. Acesso em: 23 set. 2016.

BRASIL. Técnico em Hemoterapia. Livro texto. Brasília: Ministério da Saúde, 2013.

CECCIM, Ricardo B. Educação Permanente em Saúde: desafio ambicioso e necessário. Interface: Comunicação, Saúde, Educação, Botucatu, v. 9, n. 16, p. 161-168, 2005.

CECCIM, Ricardo B; FEUERWERKER, Laura C. M. O quadrilátero da formação para a área da saúde: ensino, gestão, atenção e controle social. Physis: Revista de Saúde Coletiva, Rio de Janeiro, v. 14, n. 1, p. 41-65, 2004.

CHINELLI, Filippina; VIEIRA, Mônica; DELUIZ, Neise. O conceito de qualificação e a formação para o trabalho em saúde. In: MOROSINI, Márcia Valéria G. C. et al (org.). Trabalhadores técnicos em saúde: aspectos da qualificação profissional no SUS. Rio de Janeiro: Escola Politécnica de Saúde Joaquim Venâncio/Fundação Oswaldo Cruz, 2013, p. 23-48.

EVANGELISTA, Janete G. et al. O estado da arte da formação profissional do técnico em hemoterapia. Espaço para a Saúde: Revista de Saúde Pública do Paraná, Londrina, v. 16, n. 1, p. 48-58, 2015.

FRANCO, Maria A.; GHEDIN, Evandro. Questões de método na construção da pesquisa em educação. 2. ed. São Paulo: Cortez, 2008.

FRANCO, Maria A. Pedagogia da pesquisaação. Educação e pesquisa, São Paulo, v. 31, n. 3, p. 483-502, set.-dez. 2005.

GARCEZ, Fábio B. A PPCCIPS: a Política Pública da Coleta Complementar, Itinerante e Programada de Sangue - sob a luz da teoria do ciclo da política pública. 2008. 140f. Dissertação (Mestrado em Administração Pública) - Escola de Administração Pública e de Empresas, Fundação Getulio Vargas, Rio de Janeiro, 2008.

HABERMAS, Jurgen. Dialética e hermenêutica: para a crítica da hermenêutica de Gadamer. Porto Alegre: L\&PM, 1987.

JUNQUEIRA, Pedro C; ROSENBLIT, Jacob; HAMERSCHLAK, Nelson. História da hemoterapia no Brasil. Revista Brasileira de Hematologia e Hemoterapia, São José do Rio Preto, v. 27, n. 3, p. 201-207, jul.-set. 2005.

MATUS, Carlos. Política, planejamento \& governo. Brasília: IPEA 1993. Brasília, 1993.

MINAS GERAIS. Escola de Saúde Pública de Minas Gerais (ESP-MG). ESP-MG recebe visita 
do Ministério da Saúde e Hemominas. Belo Horizonte: ESP-MG, 2010a. Disponível em: $<$ http://www.esp.mg.gov.br/noticias/esp-mgrecebe-visita-do-ms-e-hemominas/>. Acesso em: 5 mar. 2013.

MINAS GERAIS. Escola de Saúde Pública de Minas Gerais (ESP-MG). ESP-MG participa de oficina em Brasilia. Belo Horizonte: ESPMG, 2010b. Disponível em: <http://www. esp.mg.gov.br/noticias/esp-mg-participa-deoficina-em-brasilia/>. Acesso em: 5 mar. 2013.

MINAYO, Maria C. O desafio do conhecimento científico: pesquisa qualitativa em saúde. 12. ed. São Paulo/Rio de Janeiro: Hucitec-Abrasco, 2010.

MOROSINI, Márcia Valéria G. C. et al. Trabalhadores técnicos em saúde: aspectos da qualificação profissional no SUS. Rio de Janeiro:
Escola Politécnica de Saúde Joaquim Venâncio/ Fundação Oswaldo Cruz; 2013.

PIMENTEL, Marcos A. A questão do sangue: rumos das políticas públicas de hemoterapia no Brasil e no exterior. 2006. 150f. Tese de Doutorado - Instituto de Medicina Social, UERJ, Rio de Janeiro, 2006.

PRONKO, Marcela A. et al. Formação de trabalhadores técnicos no Mercosul. Rio de Janeiro: Escola Politécnica de Saúde Joaquim Venâncio, 2011

THIOLLENT, Michel. Metodologia da pesquisaação. 2. ed. São Paulo: Cortez, 2011.

TOLEDO, Renata F.; GIATTI, Leandro L.; PELICIONI, Maria C. Mobilização social em saúde e saneamento em processo de pesquisa-ação em uma comunidade indígena no noroeste amazônico. Saúde e Sociedade, São Paulo, v. 21, n. 1, p. 206-218, jan.-mar. 2012.

Recebido em 04/11/2016

Aprovado em 22/08/2017 